\title{
PROBLEMS OF SELECTION AND DEVELOPMENT OF TALENTED STUDENTS IN THE FIELD OF INFORMATION TECHNOLOGIES
}

\section{Delov To'lqin Erkinovich}

Tashkent University of Information Technologies named after Muhammad al-Khorazmiy "Information technology education technology" assistant. dilov_t_e@mail.ru

Annotation: This article describes the intellectual potential of talented students in selected areas, the responsibility of professors and teachers for their mental development. In addition, author gives attention to democratic relations with the younger generation and teachers, which creates the basis for reaching young people high development. There is also shown an international best experience how access to positive results quick and easy. The current problems of identifying talented students in the field of ICT are mentioned.

Keywords: gifted student, student support, educational process, pedagogical assistance, pedagogical technologies, psychological and individual qualities, international experience, advanced student in information technology.

From the seventeenth century to nowadays the world system of education, special attention was given to the establishment of differentiated education. The reason of this situation is the inadequate learning content provided by the students in the learning process. 
The unequal level of psychological and individual qualities of the pupils has shown that some of the pupils have difficulty mastering the curriculum, and the inefficient use of talented pupils' time is appropriate.

During the years of independence, a special attention is being paid to the selection, training the gifted and talented students in our government at the state level.

Such actions are aimed at: "... to educate gifted youth on the basis of advanced knowledge of the world standards, to provide them with material and mental support for the development of harmoniously developed generation and highly educated specialists". ${ }^{1}$

Choosing talented children is a complex process and requires organizational correctness. While world pedagogy has certain experience in identifying gifted children, there is no single method to clarify the level of talent. At the same time, psychometric methods are used in identifying individual differences and personality traits.

In the World Education Experience, the following two systems are used to definite talented children (1.2.1-picture).

The single evaluation system focuses on the study and evaluation of some particular aspects of the child's particular attributes or activities. In this case, special tests are used individually, and the child's personality is studied in different circumstances and directions.

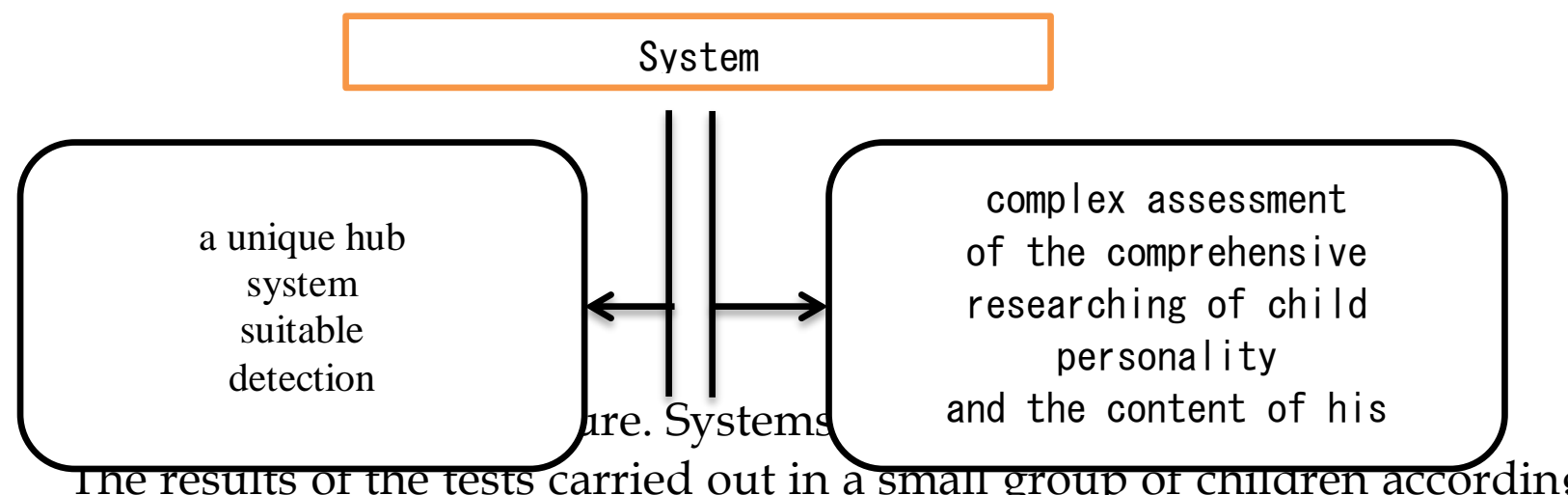

to the integrated childhood learning and comprehensive assessment of the content of the child's activities, the content of the presentation given to a particular child by the scientific supervisor as well as the position of the child

\footnotetext{
${ }^{1}$ Karimov I. A. Barkamol avlod - the foundation of the development of Uzbekistan. - T .: Oriental publishing house - publishing house, 1997. - 64 p.

Karimova V.M. Social Psychology and Social Practice / Teaching manuals. - T . : University, 1999. - 96 p.
}

Social science and humanities 
in the candidate position (his / her activity, logical thinking, speech capacity, the accuracy and other features of the action).

In the continuous education system of the Republic of Turkey, there is a tradition of measuring the level of students' ability in the following ways (1.2.2picture).

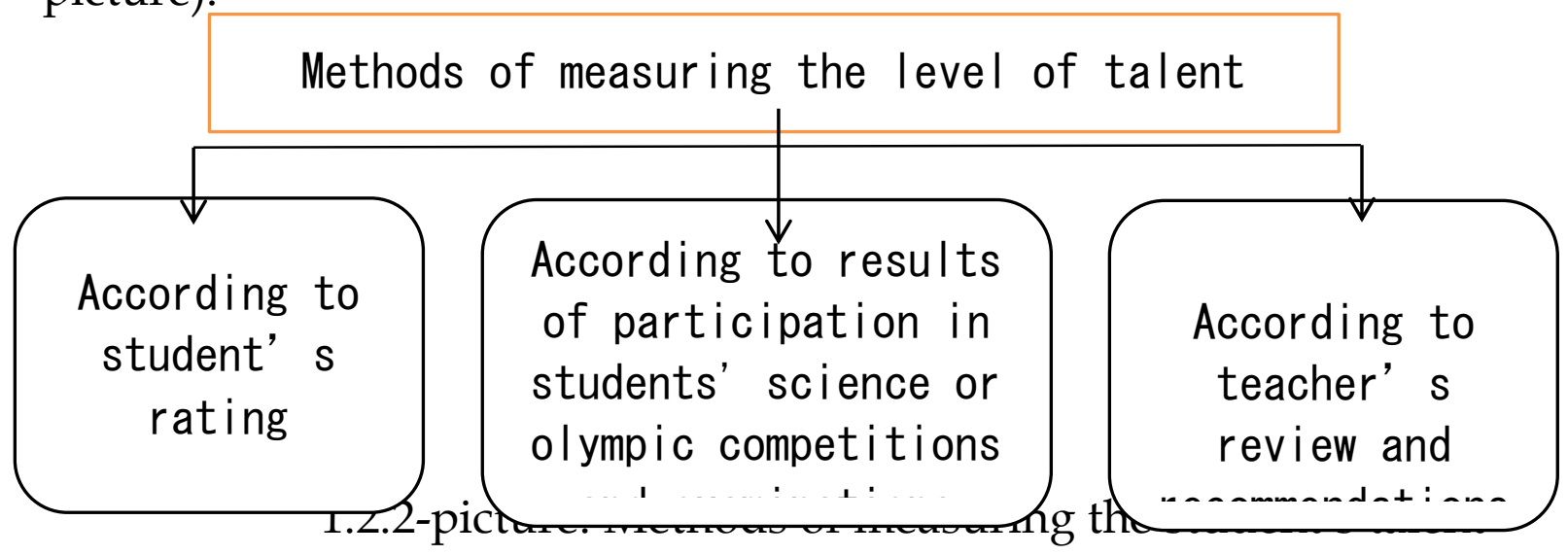

The following three aspects serve as a general criteria for all aspects of personality activity in determining the talent of a person (1.2.3-picture).

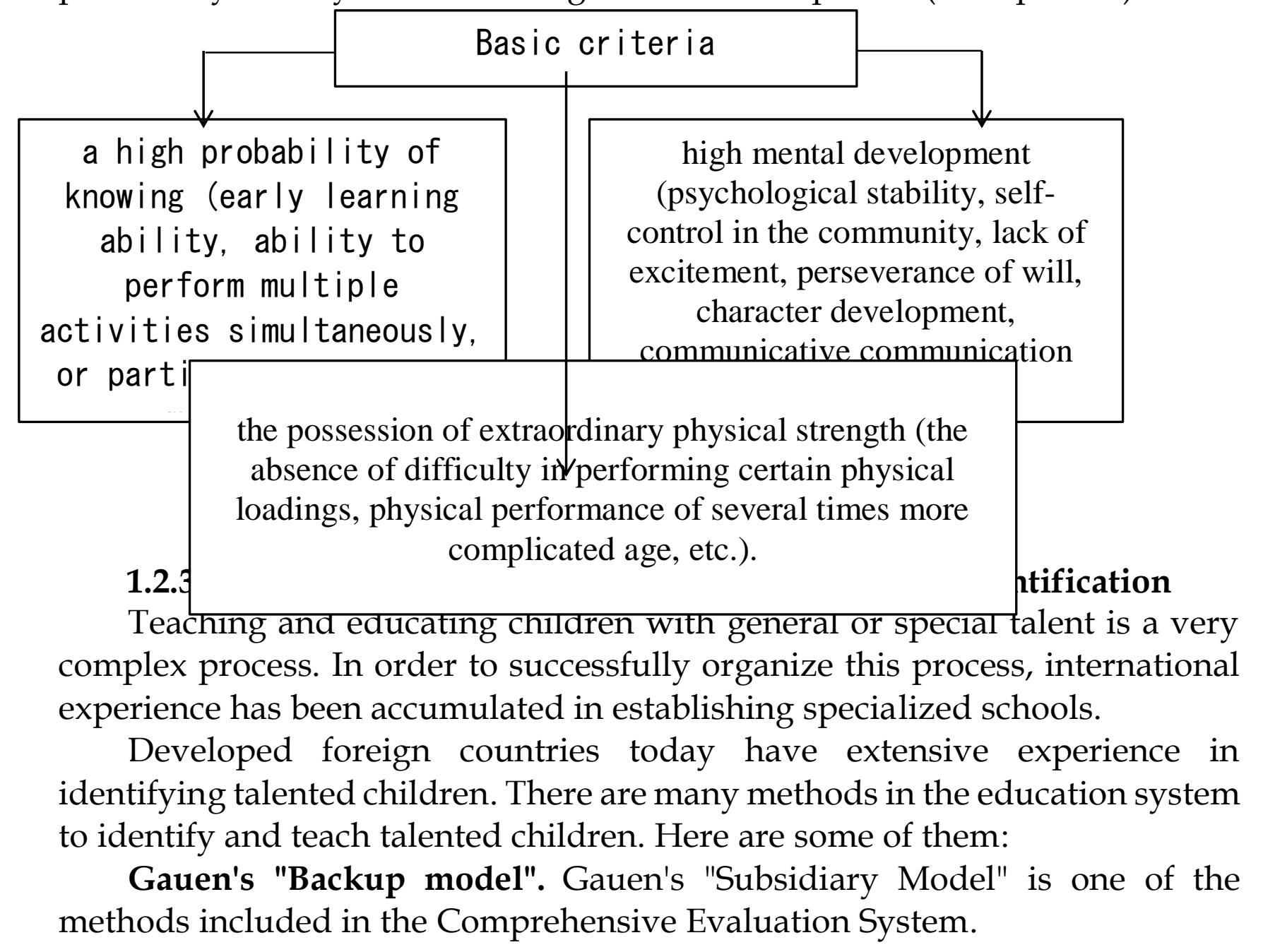

Social science and humanities

Generalization of scientific results 
Key indicators of the model are::

1) group test results;

2) class leader's recommendation;

3) re-election of candidates ${ }^{2}$.

Slosson test. It helps to measure adult and mental abilities of children. Answers to all tests are taken verbally. Some of the tasks assigned to younger children are related to the performance of certain actions by the children (e.g. paper, pencil or pencil). The test is determined by the ratio of intellectual ability to the qualities studied. The high score is 120 and more.

Vexler scale. The Vexler scale ("WPPSI" test) is a single test that allows you to define your mental abilities. It consists of two parts:

1) an estimate of five indicators such as verbal scale (mastering of particular material, understanding its content, arithmetic tasks, finding similarities, demonstration of ownership of dictionary wealth);

2) the scale of the scale of the scale (five dimensions), such as the scale of the scale (the drawings from the cubes, the finding of the labyrinths, the drawings (pictures), the essence of the proposed code (the "animal houses").

Torrens (I) creative test. Torrens (I) test is in written form and helps identify the following aspects of thinking:

1) Fast;

2) Accuracy;

3) Richness and originality of imagination.

The test is based on the correct expression of the illuminated image (card). In this case, the child should be reprogrammed correctly in a very distinctly colored picture on a separate sheet of paper.

Torrens (II) creative test. Torrens (II) is a test of verbal thinking and helps to determine the creative abilities of children and adults by verbal methods. The test has the following characteristics:

1) Having the ability to ask questions;

2) Identify the causes and consequences of situations that are appropriate to the situations described in the photographic (cardinal);

3) To offer specific ways of applying the simplest and most popular subjects in everyday life;

4) Asking unexpected questions about well-known subjects;

2 Одарённые де ти (Пер. с анг.). - М.: Прогре с с, 1991. - 381 c.

Social science and humanities

Generalization of scientific results 
5) To put forward the assumptions.

\section{Stanford-Bine Test for Primary School Schools.}

The Stanford-Bine test checks the ability of preschool and primary school students to understand certain academic subjects. The test defines the knowledge gained in the following areas:

1) math;

2) some knowledge about environment;

3) letters and sounds;

to understand oral point content.

Based on existing experience, special attention is being paid to the formation of specialized schools and ensuring their effectiveness in the years of independence in the Republic of Uzbekistan. Nowadays, the secondary education institutions specializing in teaching gifted children are among the most popular educational institutions in the Republic of Uzbekistan, continuing their activities in the following directions:
1) Social sciences;
2) Humanitarian science;
3) Math;
4) Physics;
5) Chemistry;
6) Biology;
7) Foreign languages;
8) Music;
9) Sports;

10) Dance.

The specialized schools, which are recognized as additional educational institutions, are functioning effectively in the following areas:

1) Radio communication;

2) Folk applied art (blacksmithing, carving, painting, carpentry, embroidery, gold embroidery, ceramics, etc.);

3) Fine arts;

4) Music;

5) Dance;

6) Housekeeping services (repair of electrical appliances, general nutrition, etc.).

Although there are general similarities between traditional and specialized secondary schools, they are different in their specificity. The similarities and differences are as follows: 
I. General similarities:

The Constitution of the Republic of Uzbekistan was organized in accordance with the requirements of the Law on Education; 1) Education

2) The content of the education in all disciplines is reflected in the State education standards;

3) a special attention will be paid to the provision of education and training;

4) educational institutions are supervised by the relevant higher education institutions (including district, city and regional public education departments, the Ministry of Public Education of the Republic of Uzbekistan, the Cabinet of Ministers of the Republic of Uzbekistan).

5) The educational institution is obliged to report to higher institutions and so on.

\section{Key Differences:}

1) Is organized on the basis of general or special education programs;

2) It is voluntary to study at general secondary education institutions where compulsory education is required, in specialized secondary general education institutions;

3) The majority of the hours allocated for education in the specialized secondary schools are allocated for in-depth study of special subjects;

4) Educational effectiveness:

a) Indicators of student learning in general secondary education institutions;

б) in the specialized secondary schools, it is also determined by the successful participation of students of the educational institution in various contests and examinations.

Obtaining knowledge of modern information and communication technologies has become a challenge. This is due to the fact that the demand for cadres with information skills is increasing day by day.

One of the pressing issues of higher education institutions is the low quality of general education of first-year students, many of them lacking general skills, independent work skills, intellectual activity and inadequate development of communicative culture. Therefore, it is an independent search task that serves as a crucial factor in achieving this goal, and it is important to teach students the rational and effective ways to do so. This approach is based on the systematic organization of the education system, which includes the integration of discipline, the specific goals and objectives that shape the 
professional skills of the future expert, taking into account the prospects for the development of a focused industry.

For this purpose, the elimination of the existing approaches requires intense and diligent efforts to take on a great and talentful effort to overcome the prevailing tendencies of imaginative and creative personal, talented, advanced, future teachers, bachelors and masters.

Identifying talented students is a long process related to analyzing the development of a particular student. One-time testing can not effectively determine talent.

It is therefore desirable to step by step in the process of training in special training instead of one-time talented students, to develop self-study selfgovernance in a personalized learning process and to organize independent work of students. Challenges to the talented students require the involvement of complex and highly qualified teachers. It is important to bear in mind that the criteria of talent are not determined once and for all. At the moment, the demand for teachers and bachelors is increasing for graduates of information technology-based high schools.

Now the problem of talent is very important. This, first of all, depends on society's need for extraordinary creativity. The uncertainty of the modern environment requires not only the high activity of a person, but his skill and non-standard behavior.

Early identification, education and upbringing of talented and gifted students is one of the main target of improving the education system.

However, sufficient psychological level of teacher training to work with students demonstrating non-traditional behaviors and thinking is less likely to value their personal qualities and all their work. The creative thinking of a talented student is often regarded as a divorce from norm or negativism. Experiments in many countries around the world have shown how difficult it is to rebuild the education system, alter the teacher's talent, and remove obstacles that block his talents.

There is an opinion that talented students do not need the help of adults. However, according to individual characteristics, such students are sensitive to the assessment of their behavior, attitudes and thoughts, and they are more sensitive to sensitive permits and better understand relationships and relationships. A talented student is more likely to be critical of himself, but also to those around him. So when working with gifted students, teachers need to criticize the general and criticisms. Talented students often accept non-verbal signals as a sign of rejection of others. As a result, such a student may feel 
distracted, disturbed, and always responsive. They do not have standard requirements (like everyone else), it's hard to be a conformist for them, especially if the existing norms and rules conflict with their interests. For a talented child, the statement of acceptance is not an argument. It is important for anyone to know who understands when and why.

Gifted students often put too much requirements on themselves, often fail to adapt to their goals, which can lead to emotions and behavior. In most cases rarely develop tolerance to such students. Other characteristics of these students affect their "social responsibility" and affect the "protest" position. In this context, the search for change in this position depends first of all on the fact that the teachers themselves prepare themselves to work with talented students.

You will be surprised by the indifference, even the negative attitude, to the strange and talented students who are actively involved in the development of public-private instructors and students with various developmental, behavioral and personal disadvantages. Here, of course, it is necessary to analyze the conditions of social life, because education has taken a long time to eradicate individuality. The age of new technologies requires the age to be unique, so the education system has started to embrace many innovations.

The main focus of this system is that the teacher should have not only professional but also personal characteristics to work with talented students.

The interaction of the teacher and the student is usually based on the normative-role recipes (object-object relations): "My student came to work for me, and I work as a teacher." These methods will not be accepted for gifted students. They say, "We are two people, two unique people on Earth (subjectmatter relationships) and discover the world." To do that, the teacher must really consider himself a subject.

More AA. Ukhtomsky said that our nature is being realized, so we can improve ourselves and work at any moment for personal growing. ${ }^{3}$

First, a teacher should have qualities such as actions, thinking, emotional responsiveness. They should be able to easily depart from situations or situations, methods of thinking, actions that are inconsistent with, and to develop or adopt new, specific approaches to address varying goals and ideologically and spiritually different situations.

${ }^{3}$ АА. Ухтомский, Доминанта, Цикл/серия:( Психология-классика, Издательство: Питер,2002: 328

Social science and humanities

Generalization of scientific results 
A teacher who is dedicated to developing creative abilities of students is distinguished by self-development and self-esteem, self-confidence and selfesteem. He is brave and energetic, experimental and creative. The talented students are motivated by their motivation. They will be effective in communicating with students and not through education, but through the transformation of goals and values to younger colleagues in their creative goals and values.

Both sides pay special attention to the formation of the professional and creative activity of the teacher: vocational training in the directions and personal development. If a teacher cares about professional training and has public institutions, then everyone has little idea of how to develop personality traits. However, professionalism is always accompanied by individual qualities, which enables the full realization of creative potential of a person. Therefore, let us love ourselves and take care of our personality.

The most promising opportunities for gifted students are the following types of education:

Differentiation of Differentials. The school offers several lessons in parallel for students with different capabilities. This form of education is particularly relevant to talented students who are interested in early childhood (9th grade) and who are attracted to the particular field of education at the end of adolescence.

This form of education also includes distributed and parallel secondary education in schools, such as (for example, chemical-biological, humanitarian and physical-mathematical), there are more talented students and lessonspecific classes (or classes). Includes the use of different content and methods of work, taking into account the individual approach to future professional choices based on the differentiation of the teaching process of gifted students (deep learning).

Reconfiguration of parallelism. Students of the same age are divided into groups that take into account the same capabilities for each science. One or more children may be engaged in some "developmental group" and others (for example, humanitarian) on some subjects (eg mathematics and physics). This shows that, in parallel with the same topic, children are divided into groups of new forms at one and the same time.

This form of learning is useful for students of all levels. Thus, gifted children are increasing academic achievement, improving relationships with school discipline, and promoting self-esteem. 
The rest of children also increase academic achievement, though less noticeable than gifted students. They also increase the interest in learning. Provides a comprehensive communication of children with different groups, both single and gifted children, and all children at school, which will have a positive impact on the socialization process.

The complexity of this kind of education depends on the organizational aspects, in particular the need for a sufficient number of teachers and schools. If all parallels simultaneously engage in physics, chemistry, and biology, then the school should have the same teachers and classrooms as possible classes.

Parallel selection of talented children. Each of the 5-8 children is expected to be the most successful students in parallel, each among which is placed in one of the classes, with about 20 other children.

A specially trained teacher typically works with this class, which is a complex and rich program for a talented group. The training of the main part of the class and the talented groups is carried out in parallel, it involves various tasks. This form of education, first of all, has a positive impact on the academic results of the talented group of children.

An alternative study. This form of learning involves grouping children of different ages, but not for school time, but for gifted children to communicate with their peers and to enable them to find equal rights for academic children and relevant educational content.

Through this form, students can attend a part-time school at a secondary school. The most natural option is to have talented children communicated with adults and to successfully complete all other topics with their peers. Over the past years or years, gifted children must attend university-level courses of their choice.

In this case, some of the classrooms for gifted children will be replaced by the appropriate classes. The pupil will be assessed before taking up the next part. If it has achieved a tremendous result it will be permitted to reduce its education and enrichment programs within the mandatory program. This kind of education positively influenced the development of mathematics, natural sciences and humanities.

From an organizational point of view, schoolchildren should not only teach their subjects, but also provide them with the necessary organizational development.

Students in one class divided into one or more subgroups in the same subgroup (intellectual abilities, academic achievement, etc.). This form of education has a number of advantages over others. More importantly, the Social science and humanities 
following can be highlighted: Creating the optimization conditions for all student groups (not only for talented students) due to differentiation, personalization and flexibility of the teaching process; there is no need for organizational and managerial change at the organizational level of the educational process, the availability of additional premises, professors and teachers, etc. The "mass" program, which builds talented children everywhere (large and small towns, villages, settlements, etc.).

Thus, the ability to use this form of gifted children depends on the ability of the instructor to support educational technology in small groups and the ability to allocate curricula for different groups of students in relation to their specific needs and capabilities. This is another group of students.

It should be borne in mind that the choice and implementation of this kind of education should not only depend on the capacities of a particular school, but also the choice of the optimal development strategy, taking into account the particular characteristics of the child.

In particular, the use of different forms of organization of the learning process in order to diversify the learning process, based on the idea of formation of a talented group of children in educational process, can only be effective if the content and methods have been changed. Otherwise, upbringing of talented children varies with the speed of the traditional curriculum, which can lead to more negative consequences than the fact that the true development of children is not sufficient for the needs of their personal information.

Based on the above definitions, a number of industry-specific parameters are taken into account in determining the talent of the student in the field of information technology.

As we define talented students in the field of information technology, they should be able to write independently the code of the program that is useful to the public in any programming language, not only be able to work in computer applications. At the same time, they must be able to offer innovative ideas to follow their example. Thus, taking into account the capacities of talented students in ICT direction, the expected outcomes are expected.

In order to provide more transparency in identifying talent in ICT direction, through the centralized. 


\section{References:}

1. Karimov I.A. Barkamol avlod - the foundation of the development of Uzbekistan. - T .: Oriental publishing house - publishing house, 1997. - 64 p.

2. Karimova V.M. Social Psychology and Social Practice / Teaching manuals. - T .: University, 1999. - $96 \mathrm{p}$.

3. Gifted children (Translated from English.). - Moscow: Progress, 1991. - 381

4. AA. Ukhtomsky, Dominant, Cycle / series: (C) Psychology-classics, Publisher: Piter,2002: 328 